\title{
Ionospheric Ground-based Measurement Networks
}

\author{
Ljiljana R. Cander
}

Received: 11 January 2008/ Accepted: 17 September 2008/Published online: 16 January 2009

(C) The Author(s) 2009. This article is published with open access at Springerlink.com

\begin{abstract}
Critical to the ionospheric monitoring and modelling processes whether they are related to the theoretical investigations, the space weather prediction services or the planning and operation of radio systems is a modern network of ground-based synoptic instruments making regular measurements. A short review of the principal types of ionospheric ground-based measurement networks currently available in Europe is followed by brief survey of the particular problems associated with a timely and user-friendly fashion of data delivery for assimilation purposes.
\end{abstract}

Keywords Ionospheric measurements - Modelling and forecasting · Space weather

\section{Introduction}

Some of the basic data needed to support solar-terrestrial research and associated ionospheric, propagation and space weather services are: (1) Bottomside electron density profiles $\mathrm{N}(\mathrm{h})$ from ionosondes; (2) in situ electron density measurements from satellites; (3) total electron content (TEC) measurements between ground-based receivers and the global navigation satellite system (GNSS) satellites; (4) scintillation data from scintillation receivers; (5) radio occultation data from satellite constellations; and (6) ultraviolet (UV) images of the upper atmosphere from imaging satellites. Ionospheric community has a long tradition of providing global measurements of the Earths ionosphere through the use of ground- as well as space-based remote sensing. In addition to providing global data sets for scientific research involving ionospheric data on a different scale, this community has pioneered in facilitating the use of these data by operational agencies and in incorporating them through their inclusion in data assimilation systems (Zolesi and Cander 2004, and reference therein). In this paper consideration is given to the traditional and first implemented remote sensing way of exploring our space environment by means of

L. R. Cander ( $\bowtie)$

Rutherford Appleton Laboratory, Chilton OX11 0QX, UK

e-mail: 1.cander@rl.ac.uk 
electromagnetic waves network of the vertical ionospheric sounders as well as more recent ground-based observations using GNSS signals offering the unique possibility of high resolution uniform European area coverage. Besides these currently most powerful ionospheric ground-based measurement networks, there are a growing number of others, including pulsed oblique-incidence ionospheric soundings in support of communication links and the ionospheric model that will be briefly discussed.

\section{Ionospheric Ground-based Measurement Networks}

The temporal and spatial variation in ionospheric structures have significant effects on communications and radar system operators who base their frequency management decisions on predictions and forecasting of radio propagation in the high frequency band. The modern ionosondes used in the digisonde network automatically scale the ionograms and derive important ionospheric information in real time, namely the densities and heights of the E, Es, F1, and F2 layer peaks, the electron density profile up to 1,000 km altitude, the vertical ionospheric total electron content ITEC, the maximum usable frequency (MUF) for specified distances, and the spread F status. The University of Massachusetts Lowells Center for Atmospheric Research (UMLCAR) has established a network of their DigisondeTM Portable Sounder (DPS), capable of making measurements of the overhead ionosphere and providing real-time on-site processing and analysis to characterize radio signal propagation to support communications or surveillance operations (http://ulcar. uml.edu/DIDBase/).

It was not the case until recently, hence the COST (Co-operation in the field of Scientific and Technical Research) 251 Action on Improved Quality of Service in Ionospheric Telecommunication Systems Planning and Operation. Its main objectives were to: (1) collect additional quantities and types of ionospheric data; (2) generate procedures for prediction of ionospheric models over Europe based on these data; and (3) promote their use extending the validity of the existing models to a more large area (Cander 2003).

The next COST271 Action on Effects of the upper atmosphere on terrestrial and earthspace communications has produced Space Weather: Prompt Ionospheric Database avaliable 24/7 at http://www.wdc.rl.ac.uk/cgi-bin/digisondes/cost_database.pl. Its purpose was to establish a unified database of detailed ionospheric vertical sounding observations from across Europe. The rationale for compiling the Prompt Ionospheric Database was the need to understand better how the regional and global ionosphere responds to the impact of space weather events. This is important both from the point of view of a physical understanding of the complex coupled processes involved, and from the perspective of operational systems that are affected by the ionospheric perturbations.

As a number of separate national bodies run the ionosondes across Europe, it was feasible to use data from a number of ionosondes simultaneously and create a central database to support DIAS, European Digital Upper Atmosphere Server, for specification and forecasting of the ionospheric conditions over Europe (http://www.iono.noa.gr/DIAS). DIAS project has the following main objectives: to establish a pan-European repository of raw and derived digital data describing the state of ionospheric part of the upper atmosphere; maintain historical data collections provided by most operating ionospheric stations in Europe; and to produce and distribute, based on these raw data, a number of operational products required by various user groups for ionospheric nowcasting, prediction and forecasting purposes (Belehaki et al. 2006, and reference therein). 
In addition, oblique-incidence ionospheric soundings provide a means of determining in real time the prevailing propagation modes and are useful for examining ionospheric conditions in retrospect. They are extremely important for the testing of propagation predictions for HF radio communications, ionospheric radar localization and surveillance and for validating ionospheric models in different regions (Zolesi et al. 2008).

As continuous monitoring of ionospheric conditions is essential to modelling and forecasting space weather, the worldwide use of global navigation satellite systems like the Gobal Positioning System (GPS) makes it possible to continuously monitor the total electron content (TEC) of the ionosphere and plasmasphere up to a height of about $20,000 \mathrm{~km}$ (Mannucci et al. 1998; Jakowski et al. 2002). The International GNSS Service (IGS), formerly the International GPS Service, is a voluntary federation of more than 200 worldwide agencies that pool resources and permanent GPS \& GLONASS station data to generate precise GPS \& GLONASS products. Some examples of the products can be found at SWIPPA (Space Weather Impact on Precise Positioning Applications of GNSS) web site http://www.kn.nz.dlr.de/swippa/index.htm.

\section{Conclusions}

A complete knowledge of the ionosphere demands a forecasting system. It can be based on: (1) advanced models coupled across the space weather environment leading to detailed knowledge of conditions and good prediction facilities (e.g. Physics-based data-driven models that use data assimilation techniques to specify the ionospheric plasma distributions - techniques used by the meteorologists and oceanographers for several decades); and/or (2) specific well-targeted services that provide products (specification data, postevent analysis, predictions, nowcasts or forecasts) that can be generated in real time in response to observations (e.g. COST 271 and COST296 models, DIAS, SWIPPA and so on). Critical to both approaches is a modern network of ground-based synoptic instruments making regular measurements. It is well known that operational ground-based monitoring systems are reliable and accurate thus expensive. However, many see provision of these ionospheric measurements and space weather services as a public sector task for routine monitoring of environment and dissemination of physical parameters from that monitoring as basic scientific data. Therefore, the most important message towards international scientific community in the ionospheric part of the solar-terrestrial domain is an urgent need to secure existing European ionospheric ground-based measurement networks and space weather services as well as develop new sources.

Open Access This article is distributed under the terms of the Creative Commons Attribution Noncommercial License which permits any noncommercial use, distribution, and reproduction in any medium, provided the original author(s) and source are credited.

\section{References}

A. Belehaki, Lj.R. Cander, B. Zolesi, J. Bremer, C. Juren, et al., Space Weather 4, S12002 (2006). doi: 10.1029/2006SW000270

Lj.R. Cander, Adv. Space Res. 31(4), 957-964 (2003)

N. Jakowski, S. Heise, A. Wehrenpfennig, A. Schlueter, R. Reimer, J. Atmos. Solar Terr. Phys. 64, 729-735 (2002) 
A.J. Mannucci, B.D. Wilson, D.N. Yuan, C.H. Ho, U.J. Lindqwister, T.F. Runge, Radio Sci. 33, 565-582 (1998)

B. Zolesi, Lj.R. Cander, Ann. Geophys. 47(2/3), 561-570 (2004)

B. Zolesi, G. Fontana, L. Perrone, M. Pietrella, V. Romano, G. Tutone, A. Belehaki, I. Tsagouri, S.S. Kouris, F.Vallianatos, J.P. Makris, M.J. Angling, J. Atmos. Solar Terr. Phys. 70(6), 854-865 (2008) 